\title{
LO INDIVIDUAL Y LO COLECTIVO EN LA REALIDAD BRASILEÑA
}

\author{
Carlos Alberto Bittar Filho \\ Procurador do Estado de São Paulo \\ Doutorando em Direito Civil pela Faculdade de Direito da USP
}

\begin{abstract}
Resumo:
O Brasil atual, em suas profundas modificações sociais e jurídicas, está-se movendo rumo à predominância do coletivo sobre o individual, o que não significa que tal mudança esteja sendo pacífica. Pelo contrário, o que se vê é a forte resistência do individual, que tenta deter a marcha das conquistas de caráter coletivo. Mas, apesar da luta que há atualmente entre as duas tendências antagônicas e da típica lentidão das mudanças sociais e jurídicas, o individual, cada vez mais distante da realidade brasileira, será fatalmente vencido pelo coletivo, símbolo máximo de uma nova era.
\end{abstract}

\begin{abstract}
:
Nowadays, Brazil has been faced with deep social and legal changes that will cause the predominance of collectivism over individualism, which does not mean that such a process has occurred in a pacific way. On the contrary, what is noticed is the strong resistance of individualism, which tries to avoid collectivism from progressing. However, in spite of the real fight going on these days between such opposite trends and the typical slowness of social and legal changes, individualism, more and more distant from Brazilian reality, will undoubtedly be overcome by collectivism, the major symbol of the new era.
\end{abstract}

Unitermos: Caráter coletivo, caráter individual.

Haciéndose una comparación entre el Brasil del final del siglo XIX y el Brasil del final del siglo XX, se llega fácilmente a la conclusión de que el país ha sido caracterizado por profundas modificaciones en muchos aspectos -- antes económicamente apoyado en la agricultura de exportación y socialmente basado en el patriarcalismo, es actualmente industrializado, democratizado y urbano. Todas las transformaciones por las cuales ha pasado el país reflejan la constante evolución habida en la sociedad brasileña, que está hoy superando, de manera definitiva, rasgos adquiridos en los cuatro primeros siglos de su historia. 
Hay que afirmar que tal evolución ha sido extremamente compleja; sin embargo, es posible defender la tesis de que el pueblo brasileño, en su desarrollo, tiende más y más hacia lo colectivo, quedándose lejos, por tanto, de lo individual. Eso significa que los brasileños están adquiriendo una siempre más fuerte conciencia colectiva, presupuesto fundamental para la consolidación de la nacionalidad y para la superación de los problemas de carácter general. Además, es visible la influencia de lo colectivo en el campo del derecho, por medio de importantísimas leyes sobre la protección, por ejemplo, del ambiente, del consumidor, del paisaje y del patrimonio histórico, estético y turístico.

Lo individual, herencia de los portugueses, siempre estuvo presente en la sociedad brasileña; fue uno de sus más importantes rasgos, representando y resumiendo toda la tradición de Brasil, conforme lo que expone Sérgio Buarque de Holanda:

"Os privilégios hereditários, que, a bem dizer, jamais tiveram influência muito decisiva nos países de estirpe ibérica, pelo menos tão decisiva e intensa como nas terras onde criou fundas raizes o feudalismo, não precisaram ser abolidos neles para que se firmasse $o$ princípio das competições individuais. À frouxidão da estrutura social, à falta de hierarquia organizada devem-se alguns dos episódios mais singulares da história das nações hispânicas, incluindo-se nelas Portugal e o Brasil. Os elementos anárquicos sempre frutificaram aqui facilmente, com a cumplicidade ou a indolência displicente das instituições e costumes. As iniciativas, mesmo quando se quiseram construtivas, foram continuamente no sentido de separar os homens, não de os unir. Os decretos dos governos nasceram em primeiro lugar da necessidade de se conterem e de se refrearem as paixões particulares momentâneas, só raras vezes da pretensão de se associarem permanentemente as forças ativas. "

1. Raízes do Brasil, Río, José Olympio, 1988, p. 5. 
La tradición individualista portuguesa pudo crecer y fructificar en nuestro suelo por causa del hecho de que toda la estructura social, política y económica colonial dependía directamente del latifundio, es decir, de los tierratenientes de la zona rural. ${ }^{2}$ Sobre eso, escribió con precisión Oliveira Vianna:

"Essa sociedade em formação, dispersa, incoerente, revôlta, gira realmente em tôrno do domínio rural. $O$ domínio rural é o centro de gravitação do mundo colonial. Na disseminação geral da população, lembra um pequeno núcleo solar com as suas leis e a sua autonomia organizada. Dele é que parte a determinação dos valores sociais. Nele é que se traçam as esferas de influência. Da sociedade colonial -- abstraidos os aparelhos administrativos, que se lhe ajustam, estranhos e inassimiláveis -- resta apenas, como elemento celular, o domínio rural. Sôbre êle a figura do senhor de engenhos se alteia, prestigiosa, dominante, fascinadora.

2. La sociedad brasileña fue formada en el campo, de manera que la ciudad era solamente un apéndice de él (véase, sobre el asunto, Oliveira Vianna, Evolução do Povo Brasileiro, Río, José Olympio, 1956, p. 107 y 108). Eso es comprobado totalmente por Auguste De Saint-Hilaire, que estuvo en la provincia de San Pablo ya en el siglo XIX:

“... já é sabido que, entre o rio Grande e São Paulo, atravessei as localidades denominadas -Franca, Casa Branca, Mogi-Guaçu, Mogi-Mirim, São Carlos e Jundiaí; o que até Mogi, mais ou menos, num espaço de 50 a 55 léguas, os campos são pouco habitados, quase sem culturas, sendo que os habitantes, estabelecidos de distância em distância, às margens da estrada, são geralmente homens rudes, ignorantes e estúpidos." Viagem à Província de São Paulo, trad., San Pablo, Livraria Martins, 1945, p. 111 y 112.

"Os habitantes de Mogi são, em sua maior parte, agricultores, que só vêm à cidade aos domingos." Ibidem, p. 143.

"A maior parte dos habitantes dos arredores de Campinas era constituída por agricultores" Ibidem, p. 149.

"A vila de Jundiaí é pouco extensa ... Os habitantes de Jundiaí são, em sua maioria, agricultores, que só vêm à vila aos domingos. Permaneci todo um dia útil nessa localidade .- as casas estavam todas fechadas. A esse sucedeu um dia de festa religiosa -- todas se abriram e as ruas se encheram de gente. Ibidem, p. 154.

"Em Itu, de fato, como acontece em muitissimas vilas e pequenas cidades de Goiás e de Minas Gerais: grande número de casas pertencentes a senhores de engenhos de açúcar, os quais só vêm à cidade aos domingos, a fim de ouvir missa, não se podendo mesmo, em rigor, computá-los como elementos constituintes da população." Ibidem, p. 232.

"A maior parte das casas de Pôrto Feliz pertencem a agricultores, e nessa localidade só vi um pequeno número de lojas e vendas." Ibidem, p. 244.

"Quase todos os agricultores, os habitantes de Itapetininga só ali aparecem aos domingos, o que explica porque, quando a essa localidade cheguei, encontrei-a quase deserta." Ibidem, p. 273. 
Nenhuma desprende de si, em tôrno, para as outras classes, fluidos mais intensos de sedução magnética $e$ ascendência moral."13

El latifundio fue el producto de las condiciones peculiares de las tierras brasileñas, que no permitieron el desarrollo inicial de pequeñas propiedades:

"Tudo era aquí desequilibrio. Grandes excessos e grandes deficiencias, as da nova terra. $O$ solo, excetuadas as manchas de terra preta ou roxa, de excepcional fertilidade, estava longe de ser o bom de se plantar nele tudo o que se quisesse, do entusiasmo do primeiro cronista. Em grande parte rebelde à disciplina agrícola. Áspero, intratavel, impermeavel. Os rios, outros inimigos da regularidade do esforço agrícola $e$ da estabilidade da vida de familia. Enchentes mortíferas e secas esterilizantes -- tal o regime de suas aguas. E pelas terras e matagais de tão dificil cultura como pelos rios quase impossiveis de ser aproveitados econômicamente na lavoura, na indústria ou no transporte regular de produtos agrícolas -- viveiros de larvas, multidões de insetos e de vermes nocivos ao homem.

\section{(...)}

O português vinha encontrar na América tropical uma terra de vida aparentemente facil; na verdade dificílima para quem quisesse aquí organizar qualquer forma permanente ou adiantada de economia $e$ de sociedade. Se é certo que nos paises de clima quente o homem pode viver sem esforço da abundancia de produtos espontaneos, convem, por outro lado, não esquecer que igualmente exuberantes são, nesses paises,

3. Populações Meridionais do Brasil, Río, José Olympio, 1952, vol. I, p. 85. Según el mismo escritor: "o grande domínio agrícola se erige, na sociedade vicentista, como a causa e o fundamento do poder social. Nele descansa o seu prestígio a nobreza da terra. É o único vieiro da fortuna. É a condição principal da autoridade e do mando." Ibidem, p. 88. 
as formas perniciosas de vida vegetal e animal, inimigas de toda cultura agrícola organizada e de todo trabalho sistemático e regular. ${ }^{4}$

Además de haber sido rural y basada en el latifundio, la organización colonial brasileña tuvo también dos características que no pueden ser olvidadas: la dispersión poblacional y la deficiencia de los medios de transporte y comunicación.

Respecto a la primera característica, se puede decir que fue una consecuencia lógica del régimen de distribución de tierras, conforme la opinión de Oliveira Vianna:

"... eram as terras agricultáveis distribuidas em 'sesmarias', cuja grandeza orçava, em regra, três léguas em quadra -- e daí para cima."

En relación con la deficiencia de los medios de transporte y comunicación, escribió el mismo gran maestro:

"No centro-sul -- onde o rebanho equino sempre foi relativamente escasso -- o cavalo, justamente pelo fato da sua raridade, é um sinal de distinção e fortuna: o baixo povo rural não o possui. $O$ pequeno sitiante, que adquire um 'piquira' marchador ou mesmo uma égua passista, ascende socialmente aos olhos dos seus companheiros de peonagem: está 'remediado'. Caminha talvez para a classe superior dos fazendeiros. Tão raro é entre êles o cavalo.

Esta raridade do cavalo e a conseqüente limitação do seu uso à classe superior ou média influem, entre as

4. Gilberto Freyre, Casa-Grande e Senzala, Río, José Olympio, 1954, vol. I, p. 112 y 113. Interesantes son también las observaciones de Oliveira Vianna:

"É que o lucro não é o único incentivo às explorações agrícolas nessa época. O que se procura antes de tudo é a situação social que da posse de um latifúndio decorre, as regalias que dele prevêm, a fôrça, o prestígio, a respeitabilidade. Defrontada por uma burocracia limitada e obscura e um comercio mal cotado e rudimentar, a alta classe colonial volta-se naturalmente para a lavragem das terras. Outro campo mais condigno não se abre à sua atividade." Populaçōes Meridionais..., cit., vol. I, p. 88.

5. Instituições Políticas Brasileiras, Río, José Olympio, 1955, vol. I, p. 140. 
populações do centro-sul, poderosamente sôbre a extensão dos círculos da vicinagem: estes círculos, ali são incomparavelmente mais amplos na classe superior $e$ média do que o das classes inferiores, que não possuem e não podem utilizar-se do cavalo.

Os círculos da vicinagem são determinados pela extensão máxima que a um indivíduo, peão ou cavaleiro, é dado atingir, de modo que possa estar, sem esfôrço e sem fadiga, de volta ainda com dia à sua casa de vivenda. Como no centro-sul o baixo povo dos campos não possui cavalo, o seu círculo de vicinagem é restritíssimo -- e não vai além de 4 ou 5 quilometros de raio. Os fazendeiros, os negociantes dos vilarejos, os sitiantes 'remediados', estes podem, com o cavalo, dilatar este raio para mais de 2, 3 ou 4 léguas em derredor. Fora deste limite máximo, em nossas regiões do centro-sul e do norte, desaparece o sentimento do grupo vicinal."6

Caracterizado por la dispersión y por la rarefacción, o sea, por el aislamiento de la población, el ambiente colonial permitió la perpetuación del espíritu individualista en Brasil, como bien resume Oliveira Vianna:

"Esta a estruturação ecológica, sob a qual evoluiu a nossa população colonial. Caracterizada pela rarefação e adelgaçamento da massa povoadora, pela dispersão dos moradores por uma base territorial imensa $e$ inculta, apenas percorrida calcante pede pelo povomassa e carecente quase em absoluto de comunicações espirituais, tinha que acabar, como acabou, por enformar o homem, criando-lhe um tipo humano adequado a essa disposição dispersiva, individualista $e$ atomística. E criou o homo colonialis, amante da solidão e do deserto, rústico e anti-urbano, fragueiro $e$

6. Populações Meridionais..., cit., vol. II, p. 320 y 321. 
dendrófilo, que evita a cidade e tem o gôsto do campo $e$ da floresta. Homem de que a expressão mais acabada $e$ representativa é o paulista do bandeirismo -- telúrico, eruptivo, abrupto, tal como as rochas de gneiss $e$ manganez do seu habitat formador. ${ }^{78} 8$

Siendo el derecho un típico producto cultural de la sociedad, en Brasil él absorbió la fuerte tradición individualista, lo que puede ser comprobado a través de expresivos ejemplos.

El Código Civil brasileño es una ley típicamente individualista:

"Como dissemos, o CC apresentou-se como um diploma do seu tempo. I.e., um ordenamento para a época razoavelmente atualizado, informado que foi pelas luzes dos nossos melhores doutrinadores, cujo talento em nada desmerecia o padrão científico universal.

Sucede, porém, que o seu tempo foi exatamente um tempo de transição do direito individualista para o direito de cunho social, conforme os padrões da célebre Constituição de Weimar, de 1919."

7. Instituições Políticas..., cit., vol. I, p. 145. Véase también, del mismo autor, Evolução..., cit., p. 228 y siguientes.

8. Excepción en el pueblo brasileño fue el habitante de la región del extremo sur, cuya formación, en gran parte, determinada por el militarismo y por la guerra, garantizó allí la existencia de lo colectivo:

'... o ciclo das guerras platinas exerceu sôbre a aristocracia militar do extremo-sul uma ação poderosamente diferenciadora, criando-lhe uma psicologia ou mentalidade especifica, que se distingue inteiramente da psicologia ou mentalidade das outras duas aristocracias regionais -- a das matas do centro-sul e a dos sertões nordestinos. Nos gaúchos, como vimos, os característicos dominantes da sua mentalidade regional são: o sentimento vivaz do interêsse social, primeiro; depois, a idéia clara e fecunda do poder público como órgão supremo de realização deste interêsse e como fator indispensável à própria existência coletiva." Oliveira Vianna, Populações Meridionais..., cit., vol. II, p. 257.

9. R. Limongi França, Código Civil (Histórico), in Enciclopédia Saraiva do Direito, San Pablo, Saraiva, 1977, vol. 15, p. 393. 
Dicho Código no representó una rotura en la tradición jurídica nuestra, ${ }^{10}$ lo que nos lleva a la conclusión de que el derecho privado en Brasil siempre tuvo un carácter individualista.

Lo individual también era visible en las instituciones del derecho público consuetudinario brasileño:

"-- Há uma outra instituição também principal, porque de grande 'repercussão' na nossa vida pública -$e$ por múltiplas manifestações. É a solidariedade da familia senhorial (o clã parental). Embora, originariamente, uma instituição privada, teve, e tem, muitos reflexos e influências sobre a nossa estrutura política. No curso da nossa história, vem-se transformando sensivelmente; mas, a sua floração $e$ generalização mais intensa deu-se, principalmente, no periodo colonial, nos seus primeiros séculos, todos eles trepidantes e cheios de espírito e dos feitos dessa solidariedade parental.

No Império, constituiu-se esta solidariedade como base de prestígio dos clãs eleitorais, consolidando o domínio político e partidário de determinadas famílias sôbre municípios e regiões inteiras. "11

"Os partidos locais, como se vê, surgiam por méros motivos pessoais: -- eram sempre as ambições, as vaidades e as preocupações de prestígio de família que decidiam da formação destas agremiações. Todos êles tinham um objetivo único: -- procurar para si o apoio do Governador. Éste era o centro de fôrça na Província $e$, consequentemente, nas localidades... "12

"Êstes interêsses coletivos -- bem o provamos -nunca tiveram, no ganglionarismo da nossa estrutura

10. Oliveira Vianna, Instituições..., cit., vol. II, p. 522 y 523.

11. Idem, ibidem, vol. I, p. 212. Véase también el mismo autor in Populações..., cit., p. 244.

12. Idem, Instituições..., cit., vol. I, p. 310. 
colonial, ocasião de formar-se: -- e o princípio agremiativo, que levou êstes clãs a se unirem em agrupamentos chamados 'partidos', foi o puro interêsse pessoal dos chefes de clãs, objetivado e resumido exclusivamente na conquista do poder municipal. Poder que era disputado, -- não para que realizassem qualquer interêsse geral e público das localidades (municípios); mas, apenas como meio de prestígio, de orgulho, de realce pessoal -- ou de defesa contra os adversários locais. ${ }^{\text {"13 }}$

" (...) O tipo do 'Presidente-soldado de partido' não digo que seja criação nossa; mas, é próprio dos povos, como o nosso, dominados pela 'política alimentar' e pela 'política de clã', em que o Estado ou a Administração é, antes, meio de vida a serviço dos amigos. ${ }^{114}$

Durante el ciclo del caucho (1870 1910), en la región amazónica, lo individual estuvo visiblemente presente en los llamados "reglamentos de los cauchales" sobre los cuales escribió Euclides da Cunha:

" (...) Os 'Regulamentos dos seringaes são a este propozito dolorosamente expressivos. Lendo-os, vê-se o renacer de um feudalismo acalcanhado e bronco. $O$ patrão inflexivel decreta, num emperramento gramatical estupendo, couzas assombrozas.

Por exemplo: a pezada multa de $100 \$ 000$ comina-se a estes crimes abominaveis: a) 'fazer na arvore um córte inferior ao gume do machado'; b) 'levantar o tampo da madeira na ocazião de ser cortada'; c) 'sangrar com machadinhas de cabo maior de quatro palmos' Além disto o trabalhador só póde comprar no armazem do barracão, 'não podendo comprar a qualquer outro, sob

13. Idem, ibidem, p. 331.

14. Idem, ibidem, vol. II, p. 598 y 599. 
pena de passar pela multa de $50 \%$ sobre a importancia comprada. ${ }^{15}$

Pero, como escribió José de Alencar, "tudo passa sobre a terra" ${ }^{16}$ Lo individual no podría haber seguido siendo la fuerza dominante en Brasil. Y la demostración de que una nueva realidad conquistaría el universo social y jurídico brasileño ocurrió en 1883, ya en el final del régimen monárquico:

"El hecho de que se descuidó el aspecto humano del problema para realizar el económico lo demuestra la tentativa de los estadistas del imperio para llevar coolies chinos a las plantaciones brasileñas: sustituirían a los esclavos negros. Esta nueva forma de la esclavitud se hubiera introducido en la América portuguesa si en 1883, cuando el asunto se examinó tan seriamente que vino a Brasil un tal Tong Kin Sing para discutir los detalles, no se hubiera alzado el sentimiento público en Río y en otras ciudades contra los grandes plantadores, cuyos mezquinos hábitos feudales y cuyos intereses económicos les impedían ver los intereses más amplios del público y de la nación. El año de 1883 debe considerarse como histórico en la lucha por la democratización económica de Brasil porque los intereses feudales de los plantadores de café brasileños perdieron una de sus batallas más importantes para la conservación de un sistema que había sido creado en los comienzos de la agricultura y la sociedad brasileñas, pero que llegó a ser completamente parásito y malsano al desarrollarse nuevas necesidades y nuevas condiciones de vida."

15. À Margem da História, Porto, 1913, p. 31.

16. Iracema, San Pablo, Ática, 1990, p. 87.

17. Gilberto Freyre, Interpretación del Brasil, trad., México, Fondo de Cultura Económica, 1987, p. 126 y 127. 
La lectura de este texto de Gilberto Freyre muestra claramente dos hechos de fundamental importancia para la exacta comprensión de las transformaciones por las que pasó y está pasando Brasil: la consolidación del lenguaje urbano y su predominancia sobre el lenguaje rural. Tales hechos son consecuencias de un lento proceso evolutivo cuyas raíces se encuentran aún en el siglo XVIII, según la profunda encuesta científica del mismo sociólogo:

"O periodo antes sociológico que cronológico de formação social do Brasil que procuramos estudar nestas páginas, alongando o esforço de análise e de interpretação empreendido em ensaio já publicado," -el autor se refiere al período que abarca el siglo XVIII y la primera mitad del siglo XIX -- "por um lado continuou um periodo de integração: durante ele é que se consolidou a sociedade brasileira, em torno de um Governo mais forte, de uma Justiça mais livre da pressão dos individuos poderosos, de uma Igreja que começou a falar mais alto e forte do que outrora pela voz dos seus bispos, até clamar, pela de Dom Vital, contra os excessos do proprio Governo de Sua Majestade e não apenas contra os de Irmandades $e$ Confrarias: expressão do poder dos ricos, dos letrados, dos proprios mecânicos.

Por outro, foi um periodo de diferenciação profunda -- menos patriarcalismo, menos absorção do filho pelo pai, da mulher pelo homem, do individuo pela familia, da familia pelo chefe, do escravo pelo proprietario; e mais individualismo -- da mulher, do menino, do negro - ao mesmo tempo que mais prostituição, mais miseria, mais doença. Mais velhice desamparada. Periodo de transição. $O$ patriarcalismo urbanizou-se.

Mauá e os ingleses modernizariam a técnica de transporte. Os serviços urbanos se aperfeiçoariam e com eles -- iluminação, calçamento, e, por fim, saneamento -os estilos de vida nas cidades. A vida ficaria mais livre 
da rotina doméstica. A rua -- outrora só de negros, mascates, muleques -- se aristocratizaria.

Dentro das cidades, fábricas fabricando o sabão, a vela, o pano que outrora só se fabricavam em casa, nos engenhos, vagarosa e patriarcalmente. Estrangeiros de procedencias e oficios diversos -- marceneiros, cabeleireiros, químicos, funileiros, ferreiros, modistas, fabricantes de queijo -- estabelecendo-se com oficinas, fundições, lojas. As senhoras mais chiques penteando-se não mais à portuguesa, ou quase à oriental, mas à francesa, indo ao teatro ouvir óperas cantadas por italianas a quem os estudantes ofereciam bouquets, faziam discursos, dedicavam sonetos. Os meninos educando-se em colegios -- alguns de estrangeiros -- $e$ em academias; e não apenas em casa, com o tio-padre ou o capelão. Nem simplesmente nas escolas de padres.

Periodo de equilibrio entre as duas tendencias -- a coletivista e a individualista --, nele se acentuaram alguns dos traços mais simpáticos da fisionomia moral do brasileiro. $O$ talento político de contemporização. $O$ jurídico, de harmonização. A capacidade de imitar o estrangeiro e de assimilar-lhe os traços de cultura mais finos e não apenas os superficiais. De modo geral, o brasileiro típico perdeu asperezas paulistas $e$ pernambucanas para abaianar-se em político, em homem de cidade e até em cortesão. "18

La urbanización, por consiguiente, ha sido un factor decisivo para la creación de una mentalidad diversa de la tradicional, o sea, ha participado, de manera excepcionalmente importante, de la generación de lo colectivo en Brasil; en efecto, en la ciudad se ha rompido la estructura rígida y patriarcal de la sociedad brasileña, en virtud de la exposición suya a la influencia de la cultura extranjera y de

18. Sobrados e Mucambos, Río, José Olympio, 1951, vol. I, p. 144 y 145. 
la predominancia de las relaciones humanas secundarias, de carácter contractual, sobre las primarias, de carácter familiar. ${ }^{19}$

Otro factor de extraordinario relieve para el desarrollo de lo colectivo en Brasil ha sido la expansión de los medios de transporte y comunicación. Para ello, fue decisiva la implantación del régimen republicano en 1889, que trajo una filosofía de modernidad al país y generó condiciones materiales de ejecución de los proyectos de desarrollo de los transportes y de las comunicaciones:

"Hasta que se hubo establecido la república, no empezaron a desarrollarse en Brasil una serie de atrevidos proyectos para la construcción de puertos y muelles, obras hidráulicas, planes de saneamiento, pavimentación de ciudades, drenaje y embellecimiento, conjuntamente con planes para conseguir una organización comercial más eficaz de la producción de café. Brasil se enamoró del progreso material. Y en la mayoría de eses planes puede descubrirse la impaciencia dinámica de los brasileños nacidos para la vida pública con la república de 1889: su impaciencia por hacer de Brasil un país moderno, progresista, diferente de Portugal, diferente de su estructura colonial o monárquica." 20

"Realmente, o período republicano caracteriza-se, principalmente, pelo rápido desenvolvimento dos meios de comunicação material e espiritual. Se, no ponto de

19. Sobre el proceso de modificación de la familia, escribió Carlos Alberto Bittar:

"Com a Revolução Industrial, na segunda metade do século XIX, o trabalho da mulher em fábricas e, posteriormente, em outras atividades econômicas deflagrou o processo crescente de desagregação familiar, acelerado com o êxodo rural que se lhe seguiu. A Revolução Tecnológica de nosso século, os movimentos de igualização da mulher e, mais recentemente, a denominada Revolução etária, com a liberação dos jovens, acabaram por conferir à idéia de família a sua visão atual, de caráter nuclear, restrita a certo número de pessoas.

Assim, a família de nossos dias é integrada apenas pelas pessoas que, com os pais, formam o grupo submetido à comunhão de vida, de domicilio e de patrimônio (pais e filhos não casados), em especial nos grandes centros urbanos.", Novos Rumos do Direito de Familia, in O Direito de Família e a Constituição de 1988, San Pablo, Saraiva, 1989, p. 3.

20. Gilberto Freyre, Interpretación..., cit., p. 120. 
vista da estabilidade política e das garantias do cidadão, o Império não receia um confronto com a República, esta não pode temer com o Império um cotejo no tocante ao problema da circulação. Êste é atacado com grande vigor, tanto quanto tem sido possivel, pelos dirigentes republicanos. ${ }^{.21}$

La importancia de los medios de transporte y comunicación no está solamente en el hecho de que ellos disminuyen la dispersión poblacional, sino también en el hecho de que son vehículos de irradiación de la filosofía urbana, esencialmente colectiva, y de la cultura extranjera (principalmente de la cultura europea y norteamericana).

El aumento poblacional es otro fenómeno que ha contribuido mucho para el desarrollo de lo colectivo en Brasil, como explica Oliveira Vianna:

"Nós temos uma população extremamente disseminada. $O$ processo de povoamento inicial por meio de sesmarias, vastas superficies de várias léguas de extensão, condenava-nos a esta dispersão: temos sido até agora um povo de latifundiários. Cada latifúndio, seja um núcleo pastoril, seja um centro agrícola, é um pequeno organismo social mais ou menos independente, separado dos outros por muitas léguas de distância.

Entre êsses nódulos sociais, que se difundem por todo o nosso interior, há, assim, enormes intervalos despovoados, verdadeiros trechos de deserto -- o que embaraça profundamente a regularidade da circulação geral.

21. Oliveira Vianna, Evolução..., cit., p. 296. Y prosigue el gran maestro:

"Geogràficamente mal distribuída e insuficiente, a nossa rêde ferroviária, na sua expansão nestes três decênios republicanos, denuncia, entretanto, um pensamento superior, não tanto de circulação pròpriamente dita, como de articulação das diversas regiões do país. No seu rápido esgalhar para o norte e para o sul, na sua inflexivel projeção para o âmago dos nossos sertôes, sente-se que a idéia que a anima é, antes de tudo, a de prender nos seus tentáculos de aço as diversas porçōes dissociadas da nacionalidade. O pensamento da sua expansão é, pois, menos econômica do que política." Ibidem, p. 302. 
$\hat{E}$ sses trechos de deserto só poderão ser eliminados pela colonização: ou espontânea -- devido ao aumento natural da população; ou oficial -- pela fundação de núcleos coloniais.

Ora, essa redução dos nossos espaços desérticos se está operando surda, mas eficazmente: o aumento da população nacional e o aumento do nosso coeficiente de densidade demográfica o demonstram. ${ }^{.22}$

No puede ser olvidada la fuerza del fenómeno de industrialización, que cambió completamente la organización económica del país. Unido a la urbanización, tal fenómeno rompió el monopolio de la actividad agrícola de exportación y permitió el nacimiento de nuevas clases sociales. Un buen resumen de la industrialización brasileña fue hecho por Hamilton de Mattos Monteiro:

"Ao longo de todo o século XIX e mesmo por boa parte do século $X X$, expande-se a industrialização do Brasil.

No princípio, os interesses agrários não permitem que se adote uma política ostensivamente protecionista, com tarifas suficientemente elevadas para o desenvolvimento de uma indústria autônoma. $O$ que se vê é a instalação de fábricas cujos artigos não sofrem a concorrência de produção estrangeira $e$ que se beneficiam de um mercado consumidor restrito.

Todavia, à medida que os países industrializados vão qualitativamente reorientando sua produção, abre-se a possibilidade de expandir uma indústria nacional que se dedique à fabricação daqueles artigos "desprezados". ou cujo valor fosse pequeno e, portanto, de pouco interesse para o produtor estrangeiro. Foi o caso da fabricação de tecidos de algodão, da sacaria para embalagem de café, etc. Além do mais, o país vai pouco a pouco dispondo de matérias-primas abundantes a 
preço baixo e de capitais oriundos da exportação de produtos agrícolas, notadamente o café, que precisavam ser reinvestidos.

Na primeira metade do século $X X$, conjugam-se fatores excepcionais para o processo: capital, mão-deobra, mercado relativamente concentrado, matériaprima disponivel e barata, capacidade geradora de energia e um sistema de transportes ligado aos portos. Esta concentração de fatores tem no Sudeste -- São Paulo sobretudo -- sua melhor conjugação e, na medida em que cresce e melhor se integra, a região vai receber os maiores investimentos, liderando a corrida industrial frente às demais regiões do país. ${ }^{23}$

Como se puede ver, la industrialización, la urbanización y la diversificación económica no más permiten la afirmación de que en Brasil el progreso es "gitano". ${ }^{24}$

El gobierno de Getúlio Vargas también participó del proceso de fortalecimiento de lo colectivo, porque ha enflaquecido el sistema de dominación política de las oligarquías y ha desarrolado la industrialización del país. ${ }^{25}$

Hay que mencionar la importante presencia, en las ciudades, de las clases medias, sobre las cuales escribió Francisco Carlos Teixeira da Silva:

"Tais transformações alteram, por fim, profundamente, a repartição da economia brasileira, conforme o esquema de Colin Clark: fenômeno evidenciado na análise do setor terciário, ampliado através da maior intervenção do Estado na economia e pelo desenvolvimento do setor administrativo das

23. O Aprofundamento do Regionalismo e a Crise do Modelo Liberal, in História Geral do Brasil, Río, Campus, 1990, p. 223. Sobre la formación de la clase proletaria en Río de Janeiro, véase, en nuestra literatura, Aluísio Azevedo, in $O$ Cortiço.

24. La expresión "progresso de cigano" (progreso de gitano), de Monteiro Lobato (in Cidades Mortas, San Pablo, Brasiliense, 1955, p. 3), no es más aplicable a nuestra realidad.

25. Sobre el gobierno de Getúlio Vargas, véase Sônia Regina de Mendonça, Estado e Sociedade: a Consolidação da República Oligárquica, in História Geral..., cit., p. 237 usque 242. 
empresas, do setor bancário e pela área de saúde e educação, que compensaria a sangria sofrida pela diminuição da pequena-burguesia urbana (artesãos $e$ pequenos patrões). ${ }^{26}$

Las pruebas de que lo colectivo está más y más fuerte en la sociedad brasileña pueden ser obtenidas en la observación de recientes y expresivas manifestaciones populares, como, por ejemplo, el impeachment del presidente Collor, el movimiento de los llamados caras-pintadas y el movimiento por la moralización política.

En el campo jurídico, la influencia de lo colectivo es progresiva y siempre más característica. Algunos ejemplos son muy significativos: la Ley Federal 6.938 , de 31 de agosto de 1981, que contiene reglas sobre la "política nacional del medio ambiente"; la Ley Federal 7.347, de 24 de julio de 1985, sobre la "acción civil pública", que protege el consumidor y los bienes de valor estético, histórico, turístico y paisajístico; la Ley Federal 8.078, de 11 de septiembre de 1990, que regla las relaciones de consumo; la Constitución Federal, de 5 de octubre de 1988, que dispone sobre los derechos colectivos y sociales, la función social de la propiedad, el sistema nacional de seguridad social, la educación, la cultura, los medios de comunicación y el medio ambiente $;{ }^{27}$ la Ley Federal 8.069, de 13 de julio de 1990, sobre la protección de los niños y de los adolescentes; la Ley Federal 4.717, de 29 de junio de 1965, sobre la "acción popular"; la Ley Federal 4.504, de 30 de noviembre de 1964, que es aplicable a las relaciones jurídicas agrarias, prohibiendo, por ejemplo, la obligación contractual de adquisición, por el trabajador, de bienes en el almacén del tierrateniente (art. 93, V).

En conclusión, se puede decir que el Brasil actual, en sus profundas modificaciones sociales y jurídicas, se está moviendo hacia la predominancia de lo colectivo sobre lo individual, lo que no significa que tal cambio esté siendo pacífico. Por el contrario, lo que se ve es la fuerte resistencia de lo individual, que intenta detener la marcha de las conquistas de carácter colectivo. ${ }^{28}$ Pero, a pesar de la lucha

26. A Modernização Autoritária: do Golpe Militar à Redemocratização 1964/1984, in História Geral, cit., p. 275.

27. La Constitución de 1988 representó un paso decisivo para la consolidación del régimen democrático en Brasil; en virtud de ella, el país tiene hoy aproximadamente 100 millones de electores.

28. Un ejemplo muy significativo de la resistencia de lo individual e4s el problema crónico de la concentración de tierras, lo que puede ser constatado en Francisco Carlos Teixeira da Silva: 
que hay actualmente entre las dos tendencias antagónicas y de la típica lentitud de los cambios sociales y jurídicos, lo individual, cada vez más lejos de la realidad brasileña, será fatalmente vencido por lo colectivo, símbolo máximo de una nueva era.

São Paulo, março de 1996.

"O Censo de 1960 fornece um amplo material para a análise da questão agrária no Brasil, destacando-se, desde logo, o fato de que, dos $8.510 .000 \mathrm{~km} 2$, apenas $31 \%$ encontravam-se ocupados $e$, nem sempre, de forma efetiva, com 3.350 .000 propriedades, divididas em três grandes tipos básicos:

1) pequenas propriedades (menos de 100 hectares) ...

2) as médias propriedades (as fazendas comerciais) ...

3) o latifúndio: com mais de 1.000 hectares de área, variando, entretanto, de região para regiāo, representando 0,9\% das propriedades, ocupando, porém, 47,3\% do total das terras, tendo em cultivo apenas $2,3 \%$ desta área, contribuindo apenas com $11,5 \%$ da produção e ocupando $7 \%$ da mão-deobra rural ativa. A maior parte dos latifúndios encontrava-se improdutiva, com pastos naturais -. chegando a ocupar $60 \%$ das pastagens, embora respondendo com apenas $36,6 \%$ do rebanho bovino -- ou arrendando terras a terceiros, como nas áreas de triticultura e rizicultura no sul do país ou de algodão e amendoim em São Paulo." (A Modernização Autoritária..., in História Geral..., cit., p. 282 y 283). 